\title{
CrystEngComm
}

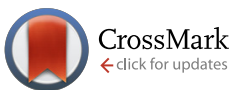

Cite this: CrystEngComm, 2016, 18 8915

Received 14th September 2016, Accepted 17th October 2016

DOI: $10.1039 / c 6 c e 01988 a$

www.rsc.org/crystengcomm

\section{Controlled synthesis of yttrium gallium garnet spherical nanostructures modified by silver oxide nanoparticles for enhanced photocatalytic properties $\dagger$}

\author{
L. Krishna Bharat, Goli Nagaraju, Kurugundla Gopi Krishna and Jae Su Yu*
}

\begin{abstract}
Spherical yttrium gallium garnet $\left(\mathrm{Y}_{3} \mathrm{Ga}_{5} \mathrm{O}_{12}\right)$ samples were prepared by a single-step hydrothermal synthesis method, and these particles were coated with silver oxide $\left(\mathrm{Ag}_{2} \mathrm{O}\right)$ nanoparticles by following a facile wet chemical approach at ambient temperature. The structural, morphological, vibrational and optical properties of the as-prepared and $\mathrm{Ag}_{2} \mathrm{O}$ modified $\mathrm{Y}_{3} \mathrm{Ga}_{5} \mathrm{O}_{12}$ samples were analyzed. From Rietveld refinement of $\mathrm{X}$-ray diffraction patterns, the crystal structure of the $\mathrm{Y}_{3} \mathrm{Ga}_{5} \mathrm{O}_{12}$ sample was refined. The morphological properties confirmed that the particles were spherical and their surfaces were covered with $\mathrm{Ag}_{2} \mathrm{O}$ nanoparticles. The $\mathrm{Ag}_{2} \mathrm{O}$ modified $\mathrm{Y}_{3} \mathrm{Ga}_{5} \mathrm{O}_{12}$ sample exhibited a relatively enhanced photocatalytic activity compared to the pure $\mathrm{Y}_{3} \mathrm{Ga}_{5} \mathrm{O}_{12}$ sample in Rhodamine $\mathrm{B}$ solution, suggesting that the introduction of $\mathrm{Ag}_{2} \mathrm{O}$ broadens the absorption of light and controls the photogenerated carrier recombination in $\mathrm{Y}_{3} \mathrm{Ga}_{5} \mathrm{O}_{12}$. These results provide a clear perspective on the synthesis of hybrid photocatalyst materials which have several ways of photogenerated carrier migration.
\end{abstract}

\section{Introduction}

Catalysis dates back to 19th century when a German researcher studied the effect of illumination of $\mathrm{ZnO}$ on the bleaching of Prussian blue. ${ }^{1}$ Meanwhile, many efforts have been devoted to understand and develop the photocatalysis process. $^{2,3}$ After these successful research efforts, for the first time, Doodeve et al. demonstrated the potentiality of $\mathrm{TiO}_{2}$ as a photosensitizer for bleaching the dyes under ultraviolet (UV) light. ${ }^{4}$ Since then, great attention has been focused on understanding and improving the photocatalytic efficiency of $\mathrm{TiO}_{2}$ materials. ${ }^{5-9}$ The increasing environmental and energy issues in the present day world provoke researchers to synthesize new photocatalytic materials which can effectively degrade the pollutants under light irradiation. Heterogeneous photocatalysis is one type of catalysis which is of low cost and has great potential for applications in water and air purification. ${ }^{10,11}$ In spite of its advantages, the rapid recombination

Department of Electronics and Radio Engineering, Kyung Hee University, Yonginsi, Gyeonggi-do 446-701, Republic of Korea. E-mail: jsyu@khu.ac.kr

$\dagger$ Electronic supplementary information (ESI) available: FE-SEM images of YGG samples synthesized in the absence and presence of EDTA, high-magnification FE-SEM images at different reaction times, FTIR spectra of YGG nanoparticles prepared at different reaction times, EDX spectrum, line scan mapping, and XPS spectrum of $\mathrm{Ag}_{2} \mathrm{O}$ modified YGG nanoparticles; PL spectra of YGG and $\mathrm{Ag}_{2} \mathrm{O}$ modified YGG; a table consisting of XPS survey data (at\%) for the elements of YGG and $\mathrm{Ag}_{2} \mathrm{O}$ modified YGG. See DOI: 10.1039/c6ce01988a of electrons inside the lattice or on the surface of the photocatalyst limits its application and commercialization. Furthermore, to improve the efficiency, cocatalyst modified photocatalysis was studied as an effective strategy. ${ }^{12}$ The principle involved in the enhanced photocatalytic activity is the formation of a space-charge layer between the semiconductor and the cocatalyst, which enriches the charge separation rate. ${ }^{12,13}$ The cocatalyst plays an important role in the photocatalytic efficiency because it functions as an oxidation or reduction site to reduce the electron-hole pair recombination. Silver dioxide $\left(\mathrm{Ag}_{2} \mathrm{O}\right)$ has a wide range of applications in several industrial fields, as an electrode material, cleaning agent, preservative, colorant, and catalyst. It has a cubic structure with $a=4.72 \AA$ and a reported band gap of approximately $1.2 \mathrm{eV}$. $\mathrm{Ag}_{2} \mathrm{O}$ has been studied by many researchers, and it acts as a good electron absorbing agent and as an efficient photosensitizer under UV and visible light irradiations, respectively. ${ }^{14,15}$ Thus, here, $\mathrm{Ag}_{2} \mathrm{O}$ is chosen as the cocatalyst for enhanced photocatalytic performance.

Recently, Jiang et al. have reported $\mathrm{Y}_{3} \mathrm{Al}_{5} \mathrm{O}_{12}: \mathrm{Ce}^{3+}$ (YAG: $\mathrm{Ce}^{3+}$ ) semiconductor particles mixed with $\mathrm{TiO}_{2}$ as an effective photocatalytic material. ${ }^{16}$ Similarly, Feng et al. also described the effect of YAG: $\mathrm{Er}^{3+}$ on the photocatalytic activity of $\mathrm{TiO}_{2}$ nanocrystals. ${ }^{17}$ The $\mathrm{TiO}_{2}$ particles showed enhanced photocatalysis with the addition of the semiconductor particles. More recently, Wang et al. have reported the influence of Gadoped $\mathrm{Er}^{3+}$ :YAG on the solar light photocatalytic activity of 
$\mathrm{TiO}_{2}{ }^{18}$ It was demonstrated that $\mathrm{Ga}$ doping can widen the absorption range of visible or infrared light and give strong UV light emission which excites $\mathrm{TiO}_{2}$ as a photocatalyst. The solar light photocatalytic activity of $\mathrm{Er}^{3+}$ :YAG in the degrada- growth mechanism of the nanoparticles, the experiment was repeated at different reaction time periods of $1,3,5,10,15$, and $20 \mathrm{~h}$. The proposed chemical reaction for the formation of YGG nanoparticles is shown below:

$$
3 \mathrm{Y}\left(\mathrm{NO}_{3}\right)_{3}+5 \mathrm{Ga}\left(\mathrm{NO}_{3}\right)_{3}+24 \mathrm{NH}_{4} \mathrm{OH} \stackrel{\text { EDTA }}{\longrightarrow} \mathrm{Y}_{3} \mathrm{Ga}_{5} \mathrm{O}_{12}+24 \mathrm{NH}_{4} \mathrm{NO}_{3}+12 \mathrm{H}_{2} \mathrm{O}
$$

tion of organic dyes depends, to some extent, on Ga doping. In this context, we attempt to synthesize ternary compound $\mathrm{Y}_{3} \mathrm{Ga}_{5} \mathrm{O}_{12}$ garnet (YGG) samples. For the synthesis of ternary compounds, accurate reaction conditions should be maintained by precisely controlling the stoichiometry of the precursors. Although the stoichiometry of the precursors is precisely controlled, compound formation is not guaranteed since it is a multi-step process with intermediate stages. This process also requires relatively high temperatures which boost the formation of aggregates. ${ }^{19,20}$ The sol-gel process eliminates the problems of chemical inhomogeneity and the difficulties in the experimental process, and the products are obtained at unexpectedly low temperatures. ${ }^{21,22}$ On the contrary, the hydrothermal method paves the way for lowering the synthesis temperature, and a narrow grain size distribution with weak agglomeration is produced. ${ }^{23,24}$ Thus, the synthesis method in which the grinding and calcination processes are annihilated is required, and the products with less aggregation in a one step process are much anticipated.

To the best of our knowledge, there were no reports found on the hydrothermal synthesis of YGG nanoparticle samples. The photocatalytic properties of these materials were studied. In this work, to enhance the photocatalytic activity, the YGG nanoparticles were modified by $\operatorname{Ag}_{2} \mathrm{O}$ and the photocatalysis was performed using Rhodamine $\mathrm{B}(\mathrm{RhB})$ as an organic dye pollutant.

\section{Experimental section}

\section{Materials}

Yttrium nitrate hexahydrate $\left(\mathrm{Y}\left(\mathrm{NO}_{3}\right)_{3} \cdot 6 \mathrm{H}_{2} \mathrm{O}\right)$, gallium nitrate hydrate $\left(\mathrm{Ga}\left(\mathrm{NO}_{3}\right)_{3} \cdot x \mathrm{H}_{2} \mathrm{O}\right)$, ethylenediaminetetraacetic acid (EDTA), ammonia solution $\left(\mathrm{NH}_{4} \mathrm{OH}(28 \mathrm{wt} \%)\right)$, silver nitrate $\left(\mathrm{AgNO}_{3}\right)$, and $\mathrm{RhB}$ were purchased from Sigma-Aldrich Co. All the chemicals were of high-purity grade and used as received without any further purification. The de-ionized (DI) water used in this experiment was obtained from a Milli-Q synthesis system (resistivity of $18.2 \mathrm{M} \Omega \mathrm{cm}$ ).

Synthesis of $\mathrm{Y}_{3} \mathrm{Ga}_{5} \mathrm{O}_{12}$ garnet nanoparticles. For the synthesis of YGG nanoparticles, the precursor solution was prepared by adding stoichiometric amounts of yttrium nitrate hexahydrate, gallium nitrate hydrate and ammonia solution in $250 \mathrm{~mL}$ of DI water. After $10 \mathrm{~min}$ of continuous stirring, EDTA was added to the precursor solution, and then the solution was stirred for $1 \mathrm{~h}$. The homogeneously mixed solution was transferred into an SUS-316 liner and placed in a stainless steel autoclave. Then, the temperature of the solution was raised to $200{ }^{\circ} \mathrm{C}$ from room temperature and maintained at this temperature for different reaction times. To study the
Synthesis of $\mathrm{Ag}_{2} \mathrm{O}$ modified $\mathrm{Y}_{3} \mathrm{Ga}_{5} \mathrm{O}_{12}$ garnet nanoparticles. The $\mathrm{Ag}_{2} \mathrm{O}$ modified YGG nanoparticles were prepared by dispersing $0.5 \mathrm{~g}$ of as-prepared YGG nanoparticles into $10 \mathrm{ml}$ of $\left(0.1 \mathrm{M} \mathrm{L}^{-1}\right) \mathrm{AgNO}_{3}$ solution. The solution was stirred for $6 \mathrm{~h}$ under ambient atmospheric conditions, and the final product was collected and dried at $60{ }^{\circ} \mathrm{C}$.

\section{Characterization}

The as-prepared samples were evaluated by using a fieldemission scanning electron microscope (FE-SEM; LEO SUPRA 55, Carl Zeiss), a transmission electron microscope (TEM; JEM-2100F, JEOL), an X-ray diffractometer (XRD; Mac Science, M18XHF-SRA), and a Fourier transform infrared (FTIR) spectroscopy system. The luminescence properties were characterized by using a fluorospectrometer (FluoroMate FS-2, Scinco). The composition and chemical states of the $\mathrm{Ag}_{2} \mathrm{O}$ modified $\mathrm{Y}_{3} \mathrm{Ga}_{5} \mathrm{O}_{12}$ samples were characterized by using an $\mathrm{X}$-ray photoelectron spectroscopy (XPS) system (Thermo Multi-Lab 2000 System).

\section{Photocatalytic activity}

The experiments intend to show the effect of the photocatalyst on organic pollutants under light illumination. Herein, RhB was used as an organic pollutant for conducting the photocatalytic experiments. The solution for photocatalysis was prepared by mixing $5 \mathrm{mg}$ of dye in $1 \mathrm{~L}$ of DI water. Then, $0.05 \mathrm{~g}$ of photocatalyst material was added to 50 $\mathrm{mL}$ of $5 \mathrm{mg} \mathrm{L}^{-1} \mathrm{RhB}$ dye solution. The solution was stirred under complete darkness for $30 \mathrm{~min}$ to reach an absorption balance. Subsequently, the solution was exposed to different light sources to observe the photocatalytic activity. UV light was obtained using a $300 \mathrm{~W}$ Xenon arc lamp (ORIEL Instruments) source with a short pass $400 \mathrm{~nm}$ filter (Edmund Optics, Barrington) and visible light with a cut-on $400 \mathrm{~nm}$ filter (FSQ-GG400, Newport Corporation). A solar simulator (SUN 3000, ABET) with a $300 \mathrm{~W}$ Xenon arc lamp was used for solar radiation. The solution was continuously stirred during the illumination process. The solution was then centrifuged to test the dye degradation percentage using a UV-vis spectrophotometer (CARY 300 Bio, Varian), and the experiment was conducted at different irradiation time periods.

\section{Results and discussion}

Fig. 1(a) shows the XRD patterns of the YGG samples synthesized at different reaction time periods of $5,10,15$, and $20 \mathrm{~h}$. The XRD patterns of all the YGG samples matched well with the standard JCPDS \#43-0512, which confirms that the samples 

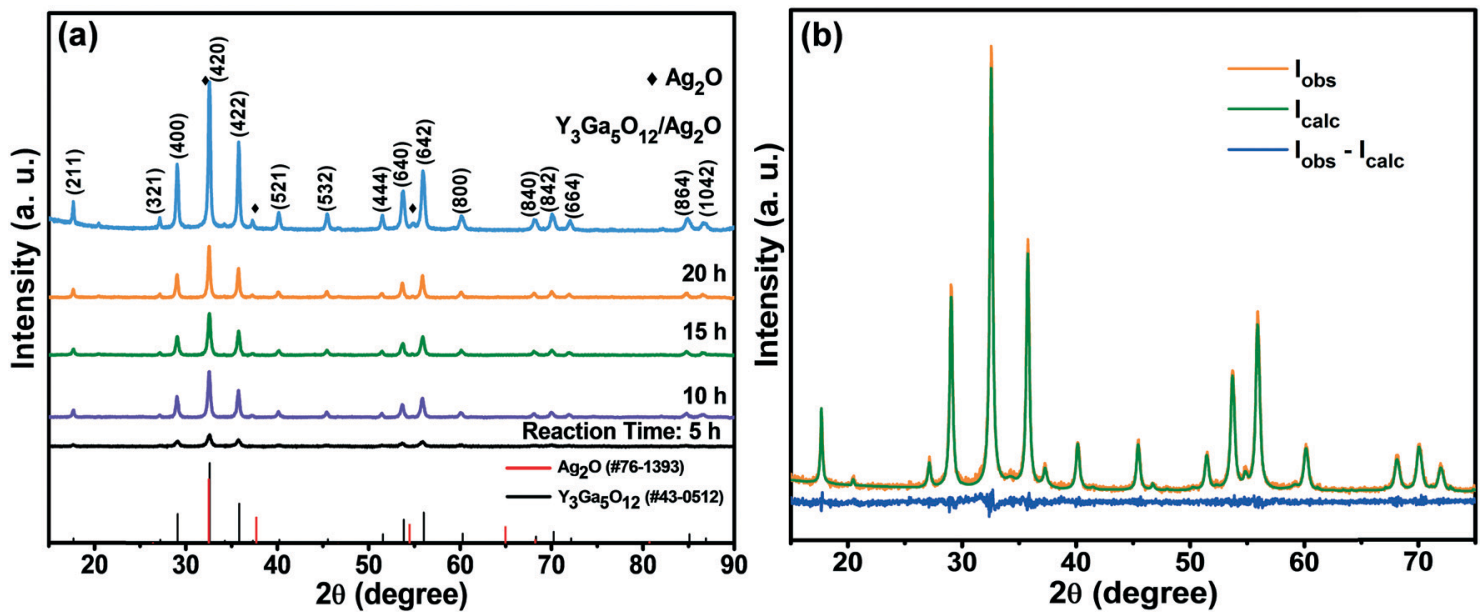

(c)

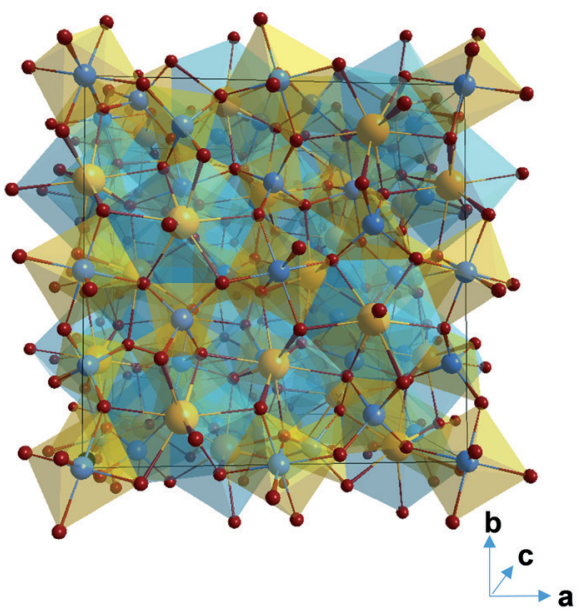

(d)

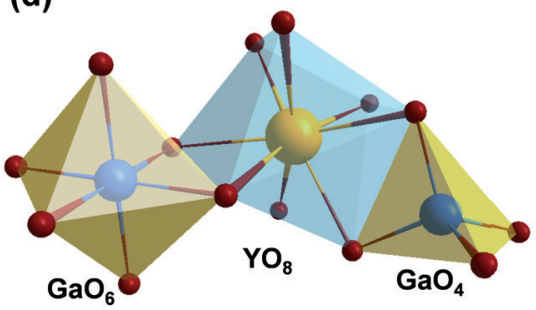

Fig. 1 (a) XRD patterns of the YGG samples prepared at different growth time periods and the $\mathrm{Ag}_{2} \mathrm{O}$ modified sample. (b) Rietveld refinement of YGG. (c) Unit cell structure of YGG. (d) Bonding arrangements of $\mathrm{Y}-\mathrm{O}, \mathrm{Ga}-\mathrm{O}, \mathrm{GaO}_{6}, \mathrm{YO}_{8}$, and $\mathrm{GaO}_{4}$.

were crystallized in the cubic phase with the $I a \overline{3} d(230)$ space group. There were no impurity peaks observed in the diffraction patterns which indicated that no mixed phases were formed, suggesting that the hydrothermal method is well suited for obtaining the pure phase YGG. The XRD pattern of the sample prepared at $5 \mathrm{~h}$ of reaction time exhibited the main diffraction peaks with weak intensity. This indicates the formation of YGG with low crystalline nature. As the reaction time increased, sharp and clear diffraction peaks appeared due to the improved crystalline nature of the YGG nanoparticles. The crystallite size was calculated by using the well-known Scherrer equation $\left(D_{h k l}=0.9 \lambda / \beta \cos \theta\right)$ by taking the dominant diffraction peaks from the XRD pattern. The average crystallite sizes of the samples prepared at different growth time periods were found to be $18.4 \mathrm{~nm}(5 \mathrm{~h}), 25.2 \mathrm{~nm}$ $(10 \mathrm{~h}), 29.1 \mathrm{~nm}(15 \mathrm{~h})$, and $34.7 \mathrm{~nm}(20 \mathrm{~h})$, respectively. The XRD pattern of $\mathrm{Ag}_{2} \mathrm{O}$ modified YGG nanoparticles is shown in Fig. 1(a) which is highly consistent with that of the YGG sample, implying that the $\mathrm{Ag}_{2} \mathrm{O}$ nanoparticles on the surface of spherical YGG nanoparticles have no effect on the crystal structure of YGG. Small peaks of $\mathrm{Ag}_{2} \mathrm{O}$ were observed in the XRD pattern of the $\mathrm{Ag}_{2} \mathrm{O}$ modified YGG, and the JCPDS card values of $\mathrm{Ag}_{2} \mathrm{O}$ (\#76-1393) are also presented in Fig. 1(a). The XRD pattern was refined by the Rietveld method using FullProf software, as can be seen in Fig. 1(b). The observed peaks were in accordance with the calculated data with a small difference found in the intensity of a few peaks. The crystal structure parameters and the fitting parameters $\left(\chi^{2}, R_{\mathrm{p}}, R_{\mathrm{wp}}\right)$ are presented in Table 1 . These

Table 1 Crystallographic and Rietveld refinement data for the YGG structure

\begin{tabular}{ll} 
Crystallographic data & \\
\hline Formula & $\mathrm{Y}_{3} \mathrm{Ga}_{5} \mathrm{O}_{12}$ \\
Crystal system & $\mathrm{Cubic}$ \\
Space group & $I a \overline{3} d(230)$ \\
$a(\AA)$ & 12.299 \\
Volume $\left(\AA^{3}\right)$ & 1860.72 \\
Rietveld data & \\
Program & FullProf suite \\
Range & $15-75^{\circ}$ \\
Step & 0.02 \\
$R_{\mathrm{p}}$ & 12.7 \\
$R_{\mathrm{wp}}$ & 17.1 \\
$\chi^{2}$ & 6.51
\end{tabular}


results reveal that the crystal structures of YGG nanoparticles are analogous to the bulk counterparts. For instance, the cell parameter $(a=12.27 \AA)$ for the bulk sample matches well that for the nanoparticle sample $(a=12.299 \AA)$. The crystal structure of YGG is shown in Fig. 1(c). The crystal structure contains $\mathrm{GaO}_{4}$ tetrahedra and $\mathrm{GaO}_{6}$ octahedra which are connected by corner sharing oxygen ions, leading to the formation of dodecahedral cavities which are filled with $\mathrm{Y}^{3+}$ ions. As a result, three distinct crystallographic cation sites are found in the YGG sample. In other words, the $\mathrm{Ga}^{3+}$ ions occupy the tetrahedral $\mathrm{S}_{4}$ site $(24(\mathrm{~d}))$ and the octahedral $\mathrm{S}_{6}$ site $(16(\mathrm{a}))$, and the $\mathrm{Y}^{3+}$ ions occupy the dodecahedral $\mathrm{D}_{2}$ site (coordination number $=8$ ). Each tetrahedral $\mathrm{Ga}^{3+}$ is connected to four octahedral $\mathrm{Ga}^{3+}$ (four fold coordination), and each octahedral $\mathrm{Ga}^{3+}$ is connected to six tetrahedral $\mathrm{Ga}^{3+}$ (six fold coordination). These $\mathrm{Y}^{3+}$ dodecahedron, $\mathrm{Ga}^{3+}$ tetrahedron, and $\mathrm{Ga}^{3+}$ octahedron are shown in Fig. 1(d). The individual anion $\left(\mathrm{O}^{2-}\right)$ is connected to a pair of dodecahedra, a single tetrahedron, and a single octahedron occupying the 96(h) site.

Fig. 2 shows the FE-SEM images of the YGG samples prepared at different growth time periods of $1,3,5$, and $20 \mathrm{~h}$, respectively. From the SEM images, it is clear that spherical nanoparticles were formed through the variation of growth time. In order to understand the role of EDTA, the YGG samples were prepared with and without EDTA. Without EDTA, the YGG sample exhibited the formation of nanosheets as shown in Fig. S1† and its morphology is similar to the shape found in the previous literature. ${ }^{25}$ When EDTA was introduced, the formation of smaller quasi-spherical shaped nanoparticles was observed. ${ }^{26,27}$ The formation of the nanoparticles is attributed to the adsorption of EDTA on the surface of YGG nuclei. The absorbed EDTA slows down the growth of YGG nuclei and produces quasi-spherical nanoparticles. Therefore, the particles further try to assemble/ aggregate, resulting in the formation of spherical nano- particles of sizes in the range of 100-300 nm. From these results, it is evident that EDTA plays an important role in the formation of spherical nanoparticles. The SEM images taken for the samples prepared without and with EDTA at $1 \mathrm{~h}$ of reaction time revealed a clear change in the morphology as can be seen in Fig. S1. $\dagger$ At $1 \mathrm{~h}$ of reaction time, many small quasi-spherical shaped nanoparticles were formed as shown in Fig. 2(a). When the reaction time was increased to $3 \mathrm{~h}$, the aggregation/assemblage of nanoparticles occurred to minimize the surface energy (Fig. 2(b)). When the reaction time was increased to $5 \mathrm{~h}$, the aggregation/assemblage process was accelerated and the amount of spherical shaped nanoparticles increased at the expense of smaller primary nanoparticles (Fig. 2(c)). When the reaction time was further increased, definite spherical shaped particles were seen due to the coalescence of primary nanoparticles and the enhanced aggregation/assemblage process. However, at longer reaction time $(20 \mathrm{~h})$, the spherical nanoparticles became bigger due to the dominant Ostwald ripening process, as shown in Fig. 2(d). The SEM images at longer reaction times of 10, 15 and $20 \mathrm{~h}$ showing the Ostwald ripening process are displayed in Fig. S2. From the obtained results, we are able to describe the growth mechanism of YGG spherical nanoparticles by involving the sequence of simultaneous nucleation, aggregation/assembly, and Ostwald ripening process.

Fig. 3 shows the schematic diagram for the growth mechanism of YGG spherical nanoparticles. Initially, a huge number of small nanoparticles are formed due to nucleation. As the reaction time increases, the nanoparticles try to assemble/aggregate. At higher reaction time, the assemblage/ aggregation process is accelerated and almost spherical shaped particles are observed. Finally, when the reaction time reaches $20 \mathrm{~h}$, definite spherical shaped YGG nanoparticles are formed due to the aggregation/assemblage and Ostwald ripening process.
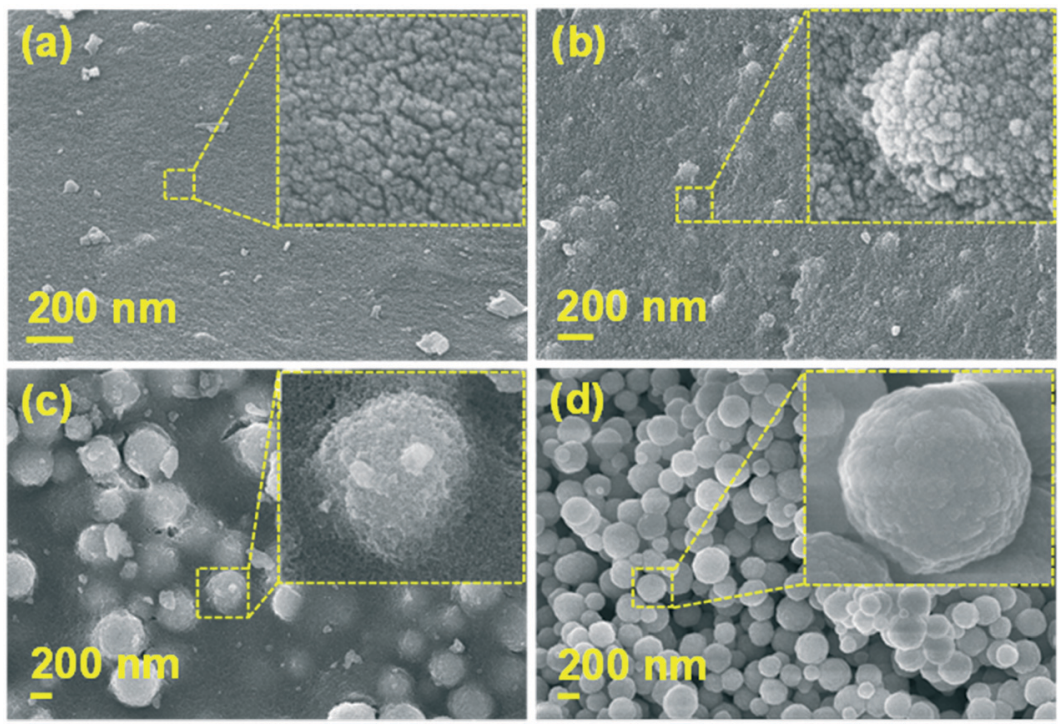

Fig. 2 FE-SEM images of the YGG samples synthesized with EDTA at different growth time periods of (a) $1 \mathrm{~h}$, (b) $3 \mathrm{~h}$, (c) $5 \mathrm{~h}$, and (d) $20 \mathrm{~h}$. 

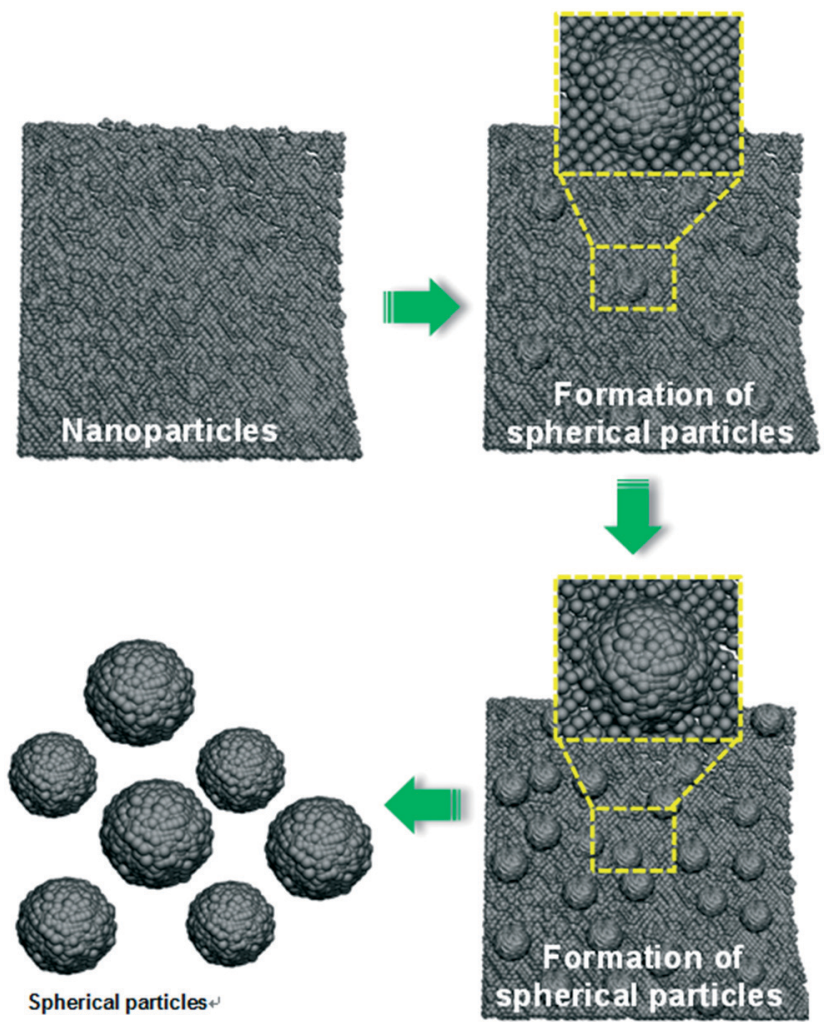

Fig. 3 Schematic diagram showing the formation of spherical YGG nanoparticles.

Furthermore, the analysis of crystal and morphological properties was carried out by performing TEM measurements as shown in Fig. 4. The distinct spherical nanoparticle forma- tion was observed as shown in the low-magnification TEM image (Fig. 4(a)). The magnified image of a single spherical nanoparticle is shown in Fig. 4(b). The high-resolution TEM (HR-TEM) image taken for the sample revealed that the nanoparticles which aggregate to form spherical structures are highly crystalline and these crystalline nanoparticles assemble to form spherical structures. The lattice fringes appeared clearly due to the crystalline nature of the nanoparticles. The $d$-spacing calculated from the HR-TEM image was $3.125 \AA$ (Fig. 4(c)), and it matched well with the XRD data corresponding to the (400) plane. The selective area electron diffraction (SAED) pattern (Fig. 4(d)) displayed a ring pattern which is formed by many dots, suggesting that the spherical particles formed are nanocrystalline in nature. ${ }^{28}$ The spatial distribution of elements in the YGG nanoparticles was studied by elemental mapping and energy dispersive X-ray (EDX) analysis. Fig. 4(e) shows the EDX spectrum obtained for a single spherical nanoparticle. The table inside the EDX spectrum shows the weight $\%$ and atomic\% distributions of the elements present in the spherical nanoparticle sample. To establish the chemical distribution in the spherical nanoparticle, elemental mapping was carried out for the single spherical nanoparticle, as shown in Fig. 4(f-i). This complete two-dimensional image of chemical zonation depicts the uniform distribution of $\mathrm{Y}, \mathrm{Ga}$ and $\mathrm{O}$ elements in the spherical nanoparticles.

FTIR spectra within the wavenumber range of 4000-450 $\mathrm{cm}^{-1}$, for samples prepared at different hydrothermal growth time periods of $5,10,15$, and $20 \mathrm{~h}$, respectively, are shown in Fig. S3. $\dagger$ From the FTIR spectra, the broad band in the longer wavenumber region $\left(3200 \mathrm{~cm}^{-1}\right)$ is due to the $\mathrm{H}-\mathrm{O}-\mathrm{H}$ stretching vibrations of the water molecule. ${ }^{29}$ The sharp and
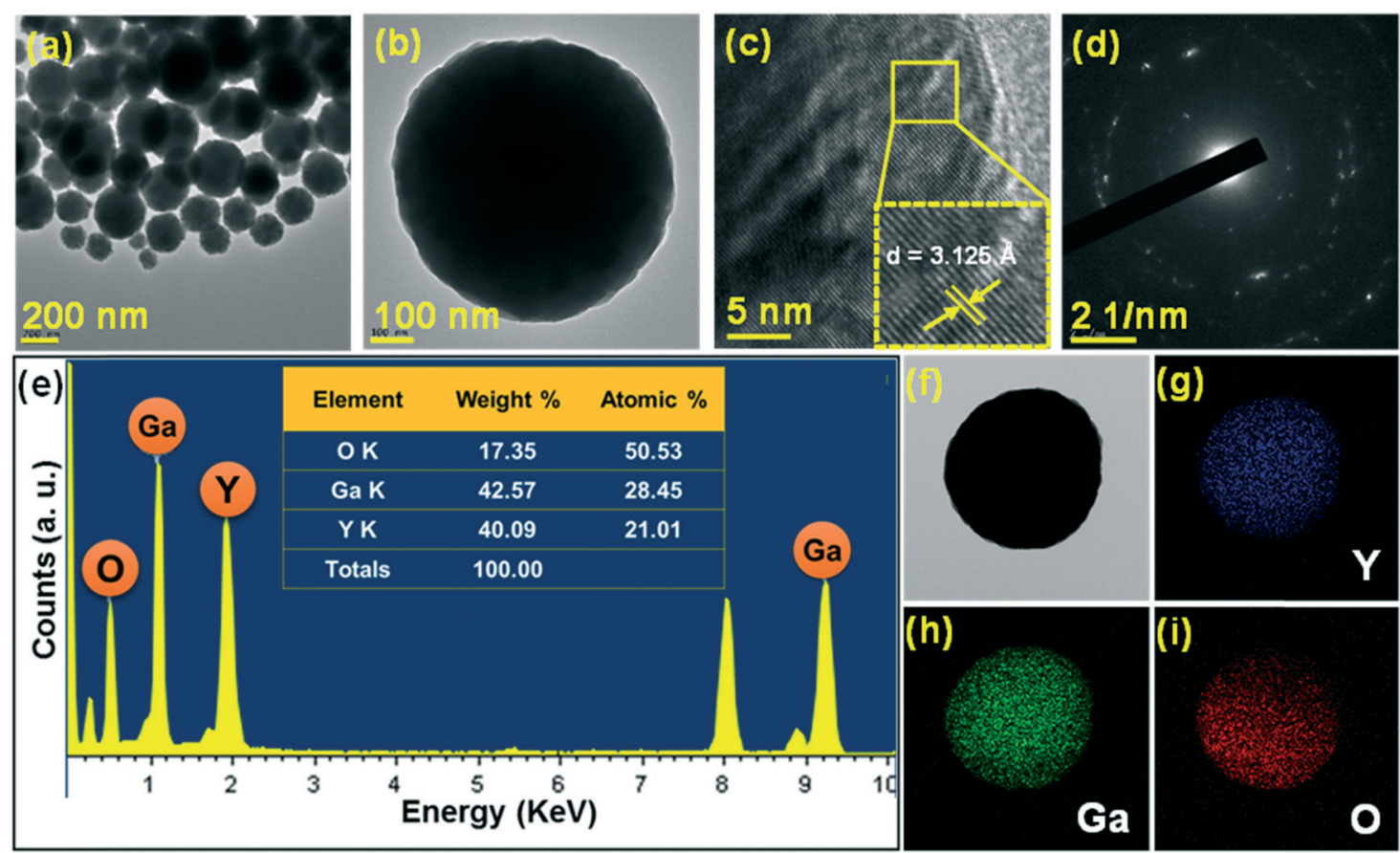

Fig. 4 (a) Low-magnification TEM image, (b) high-magnification TEM image, (c) HR-TEM image, (d) SAED pattern, and (e) EDX spectrum of the YGG sample prepared at $20 \mathrm{~h}$ of reaction time. (f) TEM image and elemental mappings of (g) yttrium (Y), (h) gallium (Ga), and (i) oxygen (O). 
intense absorption peak around $1384 \mathrm{~cm}^{-1}$ is related to the $\mathrm{C}=\mathrm{O}$ stretching vibration because of the use of EDTA in the growth process. ${ }^{23}$ The band around $1597 \mathrm{~cm}^{-1}$ is due to the $\mathrm{O}-\mathrm{H}$ stretching vibration, and $\mathrm{N}-\mathrm{H}$ deformation vibrations are also observed due to the use of ammonia in the experiment. ${ }^{30}$ Below $1000 \mathrm{~cm}^{-1}$, we can observe two bands related to the $\mathrm{Ga}-\mathrm{O}$ stretching and $\mathrm{Ga}-\mathrm{O}-\mathrm{Ga}$ bending modes. The intense band around $625 \mathrm{~cm}^{-1}$ is due to the $\mathrm{Ga}-\mathrm{O}$ stretching vibration, and the weak band below $500 \mathrm{~cm}^{-1}$ corresponds to the $\mathrm{Ga}-\mathrm{O}-\mathrm{Ga}$ bending vibration. ${ }^{31-33}$

The morphologies of the $\mathrm{Ag}_{2} \mathrm{O}$ modified YGG powders were characterized by SEM and TEM as shown in Fig. 5. Fig. 5(a) shows the schematic diagram for the formation of $\mathrm{Ag}_{2} \mathrm{O}$ nanoparticles around the surface of spherical YGG nanoparticles. The SEM image of $\mathrm{Ag}_{2} \mathrm{O}$ modified YGG nanoparticles is shown in Fig. 5(b). This indicates that the $\mathrm{Ag}_{2} \mathrm{O}$ nanoparticles were coated on the surface of all the spherical YGG nanoparticles. Fig. 5(c)-(f) show the TEM images of the $\mathrm{Ag}_{2} \mathrm{O}$ modified YGG sample. In the TEM image (Fig. 5(c)), it can be seen that the $\mathrm{Ag}_{2} \mathrm{O}$ nanoparticles were all over the surface of spherical YGG nanoparticles. The HR-TEM image is shown in Fig. 5(d), which displays two different lattice fringes for YGG and $\mathrm{Ag}_{2} \mathrm{O}$. The lattice fringes were magnified as shown in Fig. 5(e) and (f), and the planes matched well to the JCPDS card values of YGG (\#43-0512) and $\mathrm{Ag}_{2} \mathrm{O}$ (\#76-1393), respec- tively. Elemental mappings of the $\mathrm{Ag}_{2} \mathrm{O}$ modified YGG sample are shown in Fig. $5(\mathrm{~g}-\mathrm{k})$, indicating the uniform distribution of $\mathrm{Y}, \mathrm{Ga}, \mathrm{O}$, and $\mathrm{Ag}$ elements in the sample. The spatial distribution of elements was studied by the EDX spectrum which is shown in Fig. S4. $\dagger$ The linear compositional variation of the $\mathrm{Ag}_{2} \mathrm{O}$ modified YGG was further supported by the line scan mapping as shown in Fig. S5.†

Fig. 6 shows the XPS spectra of the YGG and $\mathrm{Ag}_{2} \mathrm{O}$ modified YGG samples to study the electronic states of the elements and elemental compositions. The survey scan spectra shown in Fig. 6(a) exhibited distinct elements of $\mathrm{Y}, \mathrm{Ga}$, and $\mathrm{O}$ for the YGG, while the $\mathrm{Ag}_{2} \mathrm{O}$ modified YGG sample showed an extra element, $\mathrm{Ag}$, along with $\mathrm{Y}, \mathrm{Ga}$, and $\mathrm{O}$, signifying the presence of $\mathrm{Ag}_{2} \mathrm{O}$. The trace amounts of $\mathrm{C}$ in the XPS spectra are due to the extrinsic hydrocarbon during the XPS measurement. Fig. 6(b)-(e) show the high-resolution XPS curves of the $\mathrm{Y} 3 \mathrm{~d}$, Ga 2p, Ag 3d, and $\mathrm{O}$ 1s for the corresponding samples. Herein, all the spectral curves were fitted with a Gaussian method. As shown in Fig. 6(b), the peaks at binding energy values of 157 and $159.11 \mathrm{eV}$ for $\mathrm{Y} 3 \mathrm{~d}_{5 / 2}$ and $3 \mathrm{~d}_{3 / 2}$ revealed the +3 oxidation state of $Y$. The spin orbit splitting of $2.11 \mathrm{eV}$ is observed, and it is in agreement with previous reports. $^{34}$ In addition, the $\mathrm{Ga} 2 \mathrm{p}$ spectrum exhibited the spin-orbit splitting into $2 \mathrm{p}_{3 / 2}$ and $2 \mathrm{p}_{1 / 2}$ at binding energy values of 1117.8 and $1143.5 \mathrm{eV}$, and the $\mathrm{O}$ 1s peak at 530.39
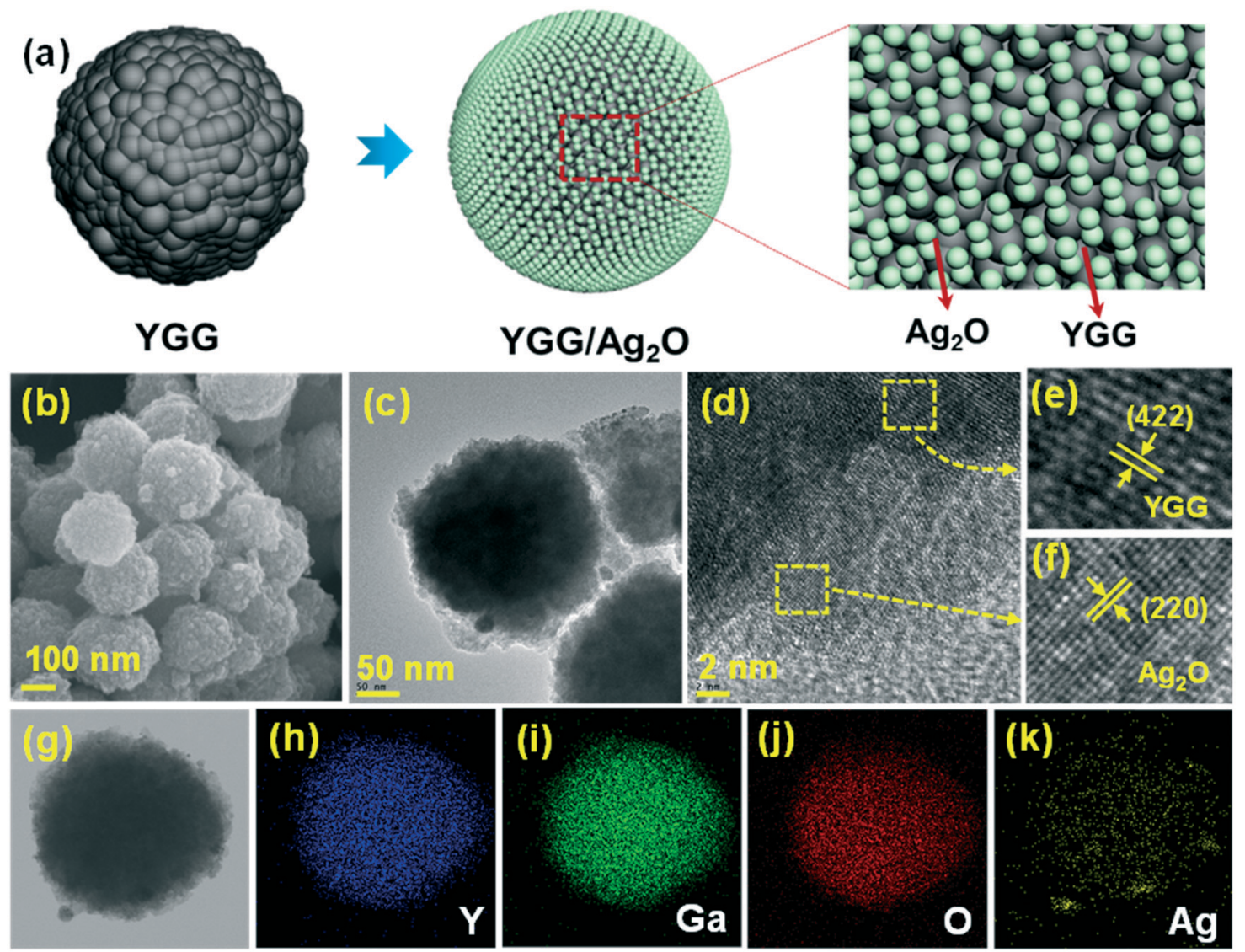

Fig. 5 (a) Schematic diagram showing the arrangement of $\mathrm{Ag}_{2} \mathrm{O}$ nanoparticles on $\mathrm{YGG}$ nanospheres. (b) SEM image, (c-f) TEM images, and (g-k) elemental mappings. 

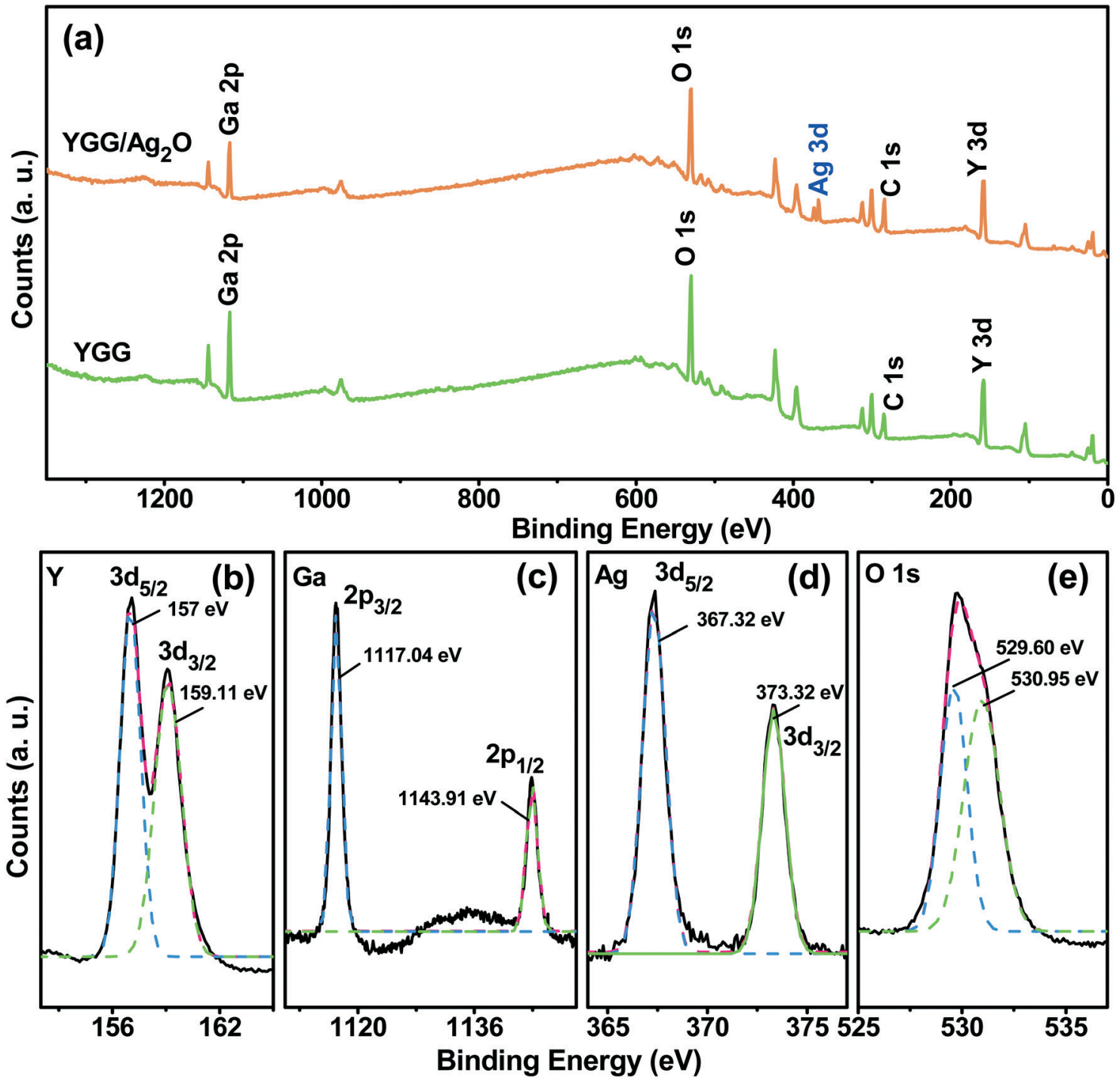

Fig. 6 (a) Survey scan XPS spectra of the YGG and $\mathrm{Ag}_{2} \mathrm{O}$ modified YGG samples, and high-magnification XPS spectra of (b) Y $3 \mathrm{~d}$, (c) Ga $2 \mathrm{p}$, (d) $\mathrm{Ag}$ $3 \mathrm{~d}$, and (e) $01 \mathrm{~s}$.

eV was observed, indicating that the Ga exists in the +3 oxidation state. The high-resolution spectrum in Fig. 6(d) shows two distinct peaks at 368.2 and $374.6 \mathrm{eV}$, which are attributed to the $\mathrm{Ag} 3 \mathrm{~d}_{5 / 2}$ and $3 \mathrm{~d}_{3 / 2}$ spin-orbit doublets of the $\mathrm{Ag} 3 \mathrm{~d}$. In general, the oxidation states of $\operatorname{Ag}(\mathrm{I})$ and $\operatorname{Ag}(0)$ are mainly observed in the binding energy values of 367.5-368.4 eV, which confirms that the $\mathrm{Ag}$ exists in the +1 oxidation state and it is similar to the values reported for $\mathrm{Ag}^{+}$in $\mathrm{Ag}_{2} \mathrm{O} .{ }^{35}$ Clearly, the asymmetric $\mathrm{O}$ 1s spectrum of the $\mathrm{Ag}_{2} \mathrm{O}$ modified YGG showed two peaks (Fig. 6(e)), i.e. one main peak at $529.6 \mathrm{eV}$ along with a shoulder peak at $530.95 \mathrm{eV}$ unlike the $\mathrm{O}$ 1s of YGG which indicates the formation of $\mathrm{Ag}_{2} \mathrm{O} .^{36,37}$ The $\mathrm{O}$ 1s spectra of the YGG and the $\mathrm{Ag}_{2} \mathrm{O}$ modified YGG are shown in Fig. S6. $\dagger$ The quantitative analysis of atomic percentage (at\%) of elements present in the YGG and $\mathrm{Ag}_{2} \mathrm{O}$ modified YGG samples is shown in Table S1. $\dagger$

The photoluminescence (PL) excitation (PLE) and emission spectra of the as-prepared spherical YGG nanoparticle sample are shown in Fig. 7(a). The PLE spectrum was mea- sured within the wavelength range of 200 to $415 \mathrm{~nm}$ by monitoring the emission wavelength of $435 \mathrm{~nm}$. The excitation spectrum shows a broad band centered at a wavelength of $355 \mathrm{~nm}$. Likewise, the PL emission spectrum was observed at an excitation wavelength of $355 \mathrm{~nm}$. A broad band from 390 to $650 \mathrm{~nm}$ centered at $435 \mathrm{~nm}$ was observed in the blue region of the emission spectrum. A similar blue emission by the host lattice has also been reported in YGG:Dy ${ }^{3+}$ phosphors by Chengli et al. This is attributed to the presence of self-activated $\mathrm{Ga}-\mathrm{O}$ luminescent centers in the host lattice. ${ }^{38}$ In addition, there were other previous reports where they have shown the same broad band in the blue region of the PL emission spectrum. Krishna et al. showed that the blue emission from $\mathrm{ZnGa}_{2} \mathrm{O}_{4}$ crystals is due to the distorted octahedral $\mathrm{Ga}-\mathrm{O}$ groups which act as self-activated luminescent centers. $^{39}$ The $\left(\mathrm{Gd}_{2} \mathrm{O}_{3}\right)_{x}\left(\mathrm{Ga}_{2} \mathrm{O}_{3}\right)_{(1-x)}$ thin films exhibited a broad band which stretches from 350 to $500 \mathrm{~nm}$, and the emission peak changed with the $x$ concentration. As the 

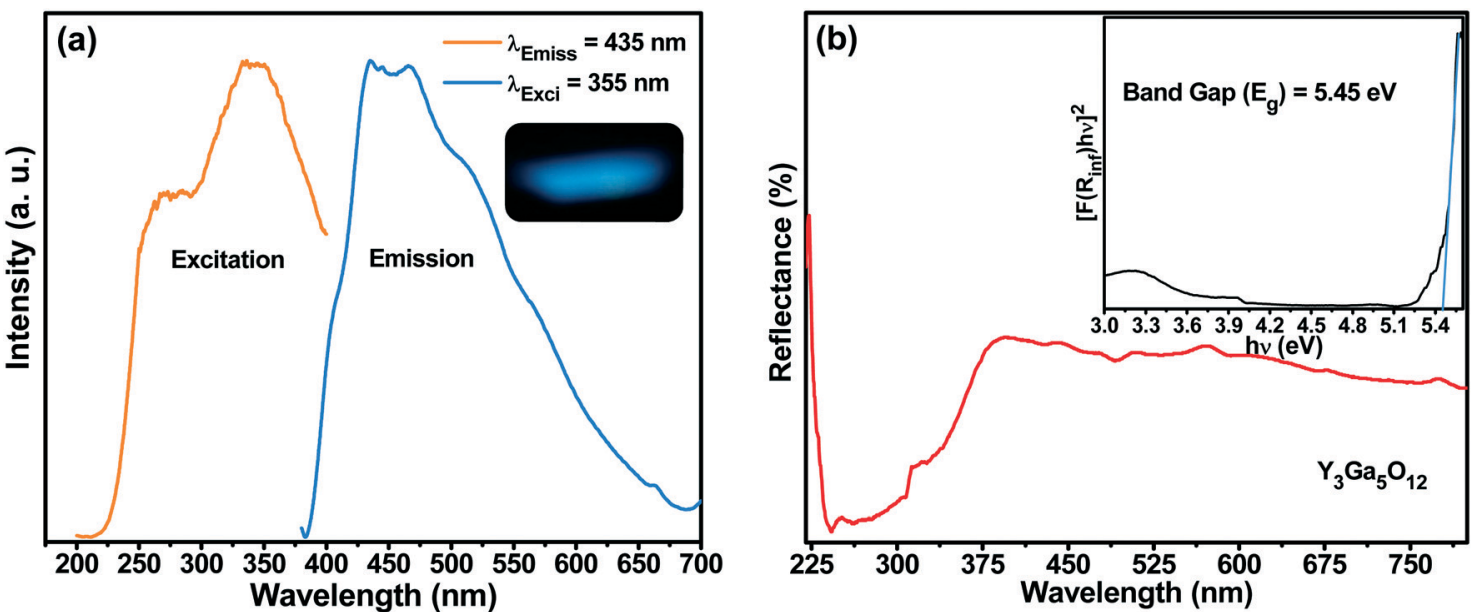

Fig. 7 (a) PLE and PL emission spectra of the YGG sample (the inset shows the emission color of the sample). (b) DR spectra of the YGG sample (the inset shows the band gap of the samples).

$x$ concentration was increased to $\sim 37.5 \%$, the emission peak was shifted from 430 to $397 \mathrm{~nm}$ and it remained constant with further increase. ${ }^{40}$ Lü et al. also reported the blue emission from the $\mathrm{Gd}_{3} \mathrm{Ga}_{5} \mathrm{O}_{12}$ host lattice when observed at an excitation wavelength of $335 \mathrm{~nm} .{ }^{32}$ Furthermore, in reports on $\mathrm{Ga}_{2} \mathrm{O}_{3}$ under UV light illumination, the blue emission was observed due to the presence of oxygen vacancies. ${ }^{41-43}$ The facts mentioned above imply that the broadband blue emission observed for the as-prepared YGG nanoparticle sample is attributed to the $\mathrm{Ga}-\mathrm{O}$ groups existing in the host lattice.

Fig. 7(b) shows the diffused reflectance (DR) spectrum within the range of $220-800 \mathrm{~nm}$ for the YGG nanoparticle sample. The band observed below $400 \mathrm{~nm}$ is due to the host material. Based on the DR spectrum, the band gap of the sample was calculated from the well-known Kubelka-Munk theory. The Kubelka-Munk function $F\left(R_{\infty}\right)$ is given as follows: ${ }^{44}$

$$
F\left(R_{\infty}\right)=\frac{\left(1-R_{\infty}\right)^{2}}{2 R_{\infty}}=\frac{K}{S},
$$

where $R_{\infty}$ is the diffuse reflectance of the sample. It is the ratio of scattered light from a layer of sample and an ideal nonabsorbing reference sample as a function of wavelength $(\lambda)$ ( $R_{\infty}=R_{\text {sample }} / R_{\text {reference }}$. $K$ is the absorption coefficient and $S$ is the scattering coefficient. The well-known Tauc relation which relates the energy band gap $\left(E_{\mathrm{g}}\right)$ and the linear absorption coefficient $(\alpha)$ of a material is given below:

$$
\alpha h \vartheta=A_{1}\left(h \vartheta-E_{\mathrm{g}}\right)^{n / 2},
$$

where $\vartheta$ is the photon energy and $A_{1}$ is constant. $K$ becomes $2 \alpha$ when the material scatters in a perfectly diffuse manner. $S$ is considered as a constant with respect to $\lambda$, and utilizing eqn (2) and (3), the following equation can be obtained:

$$
\left(F\left(R_{\infty}\right) h \vartheta\right)^{2}=A_{2}\left(h \vartheta-E_{\mathrm{g}}\right)^{n}
$$

Here, the values of $n=1,3,4,6$ for direct allowed, direct forbidden, indirect allowed and indirect forbidden transitions, respectively, and $n=2$ for non-metallic materials. The plot is drawn between $\left(F\left(R_{\infty}\right) h \vartheta\right)^{n}$ and $h \vartheta$ for different values of $n$ and it fits best for $n=1$, suggesting the nature of band transitions as direct. ${ }^{44}$ The band gap was found to be $5.45 \mathrm{eV}$ as shown in the inset of Fig. 7(b).

In order to establish the photocatalytic activity of YGG nanoparticles, the YGG sample prepared at the reaction time of $20 \mathrm{~h}$ was chosen. Fig. 8(a) shows the absorption spectra of the RhB dye solution with the YGG photocatalyst under UV light irradiation. The absorption peak of the dye was observed in the wavelength range of 450 to $600 \mathrm{~nm}$ centered at $553 \mathrm{~nm}$. The peak intensity decreased as the irradiation time increased, and the absorption peak almost disappeared at 9 $\mathrm{h}$ of irradiation time, indicating the complete degradation of the $\mathrm{RhB}$ dye. The photodegradation rate $\left(C / C_{\mathrm{o}}\right)$ in the presence and absence of the photocatalyst is shown in the inset of Fig. 8(a). Here, $C$ and $C_{\mathrm{o}}$ are the intensities of the RhB absorption peak in the presence and absence of UV light. The photodegradation rates of 97.5 and $25 \%$ were obtained for the RhB dye solutions with and without the YGG photocatalyst at the irradiation time of $9 \mathrm{~h}$. The photodegradation of the dye in the presence of YGG takes a long time of $9 \mathrm{~h}$ for its complete degradation. To enhance the degradation efficiency, the YGG particles were modified with $\mathrm{Ag}_{2} \mathrm{O}$. Fig. 8(b) shows the photocatalytic activity of the $\mathrm{Ag}_{2} \mathrm{O}$ modified YGG sample under UV light irradiation. As shown in Fig. 8(b), it is clear that the photodegradation efficiency was improved and the dye was degraded within the time of $6 \mathrm{~h}$. The reaction kinetics of photocatalytic degradation can be obtained by the pseudo-first order rate equation:

$$
\ln \left(C / C_{\mathrm{o}}\right)=-k t
$$

where $k$ is the rate constant and $t$ is the irradiation time. The plot was drawn between $\ln \left(C / C_{\mathrm{o}}\right)$ and irradiation time and fitted linearly as shown in Fig. S8. $\dagger$ The estimated rate 

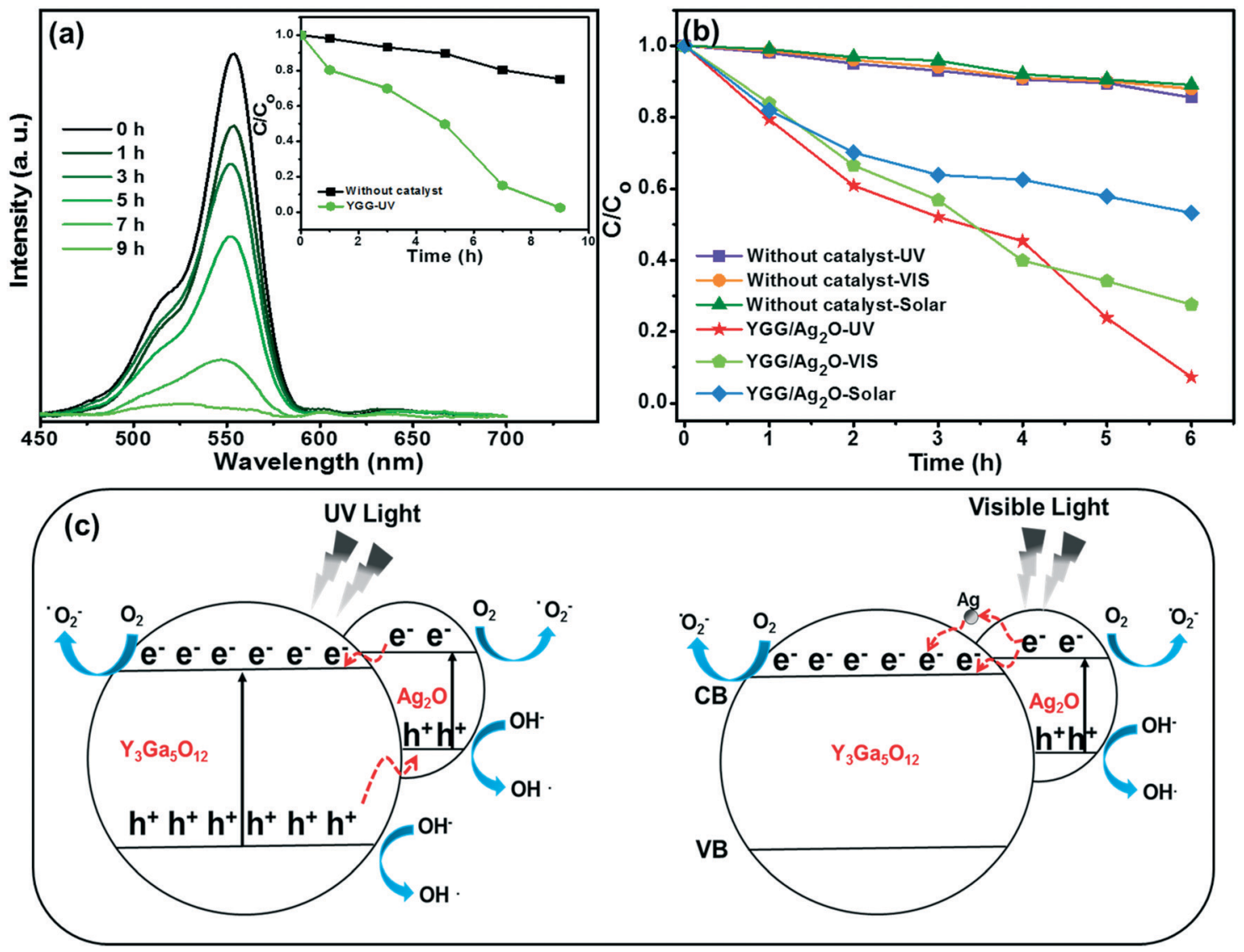

Fig. 8 (a) UV/vis absorption spectra of the RhB solution in the presence of YGG spherical nanoparticles under UV radiation. The inset of (a) shows the photodegradation rate curves. (b) Photodegradation rates of the RhB dye solution in the presence and absence of $\mathrm{Ag}_{2} \mathrm{O}$ modified $\mathrm{YGG}$ nanoparticles under different light radiations. (c) Photocatalysis mechanism under UV and visible light.

constant and linear correlation coefficient $\left(R^{2}\right)$ are shown in Table S2. $\uparrow$ The $R^{2}$ values were found to be greater than 0.8988 , supporting the pseudo-first order rate kinetics. When UV light is irradiated, the YGG spherical nanoparticles are excited and generate electrons $\left(\mathrm{e}^{-}\right)$and holes $\left(\mathrm{h}^{+}\right)$. These $\mathrm{e}^{-}-\mathrm{h}^{+}$ pairs recombine quickly; hence, the photocatalytic activity is very low for YGG spherical nanoparticles. When the $\mathrm{Ag}_{2} \mathrm{O}$ modified YGG sample was irradiated with UV light, both the YGG and $\mathrm{Ag}_{2} \mathrm{O}$ get excited. The photogenerated $\mathrm{e}^{-}$move from the conduction band of $\mathrm{Ag}_{2} \mathrm{O}$ to $\mathrm{YGG}$ and $\mathrm{h}^{+}$from the valance band of YGG to $\mathrm{Ag}_{2} \mathrm{O}$, thus efficiently separating $\mathrm{e}^{-}$and $\mathrm{h}^{+}$. The $\mathrm{e}^{-}$and $\mathrm{h}^{+}$separation was further confirmed by taking the PL spectra of the YGG and the $\mathrm{Ag}_{2} \mathrm{O}$ modified YGG. The PL spectrum actually corresponds to the $\mathrm{e}^{-}$and $\mathrm{h}^{+}$transfer behavior, consequently symbolizing the recombination and separation of $\mathrm{e}^{-}$and $\mathrm{h}^{+}$. The PL intensity of the $\mathrm{Ag}_{2} \mathrm{O}$ modified YGG is less than that of the original YGG sample, as shown in Fig. S7.† This suggests that the recombination of exciton pairs was limited. Therefore, the excited $\mathrm{e}^{-}$and $\mathrm{h}^{+}$lifetime can be extended, giving rise to higher photocatalytic activity than the as-prepared YGG spherical nanoparticles. Later on, the $\mathrm{e}^{-}$react with adsorbed $\mathrm{H}_{2} \mathrm{O}$ and $\mathrm{O}_{2}$ and produce superoxide radical anions like $\mathrm{O}_{2}^{--}$. The $\mathrm{h}^{+}$were held by $\mathrm{OH}^{-}$and $\mathrm{H}_{2} \mathrm{O}$, resulting in the production of $\mathrm{OH}$ species (strong oxidizing agent). Moreover, the loaded $\mathrm{Ag}_{2} \mathrm{O}$ generates $\mathrm{O}_{2}$ species which elevate the creation of $\mathrm{OH}$ species, and enhances the photocatalytic activity under UV irradiation.

Subsequently, when the $\mathrm{Ag}_{2} \mathrm{O}$ modified YGG particles are illuminated with visible light, $\mathrm{Ag}_{2} \mathrm{O}$ alone gets excited due to its small band gap $(1.2 \mathrm{eV})$. The excited $\mathrm{e}^{-}$move from the conduction band of $\mathrm{Ag}_{2} \mathrm{O}$ to $\mathrm{YGG}$ and the $\mathrm{h}^{+}$remain in the valence band, thus separating them efficiently. Furthermore, the photogenerated $\mathrm{e}^{-}$are transferred to lattice $\mathrm{Ag}^{+}$due to the higher positive potential of $\mathrm{Ag}^{+} / \mathrm{Ag}$. The $\mathrm{Ag}^{+}$acts as a sacrificial reagent for the efficient evolution of oxygen. In the present work, the trace amount of $\mathrm{Ag}^{+}$in $\mathrm{Ag}_{2} \mathrm{O}$ was reduced to metallic Ag in situ by photogenerated $\mathrm{e}^{-}$during the experiment. The $\mathrm{e}^{-}$are transferred from $\mathrm{Ag}_{2} \mathrm{O}$ to metallic $\mathrm{Ag}$ and then to YGG, leading to the separation of $\mathrm{e}^{-}$and $\mathrm{h}^{+}$. Therefore, photocatalytic activity is observed under visible light. The possible mechanism supposed for enhanced photocatalytic activity is schematically shown in Fig. 8(c). At the same time, the relevant formula reactions are as follows: ${ }^{45-47}$

$$
\mathrm{Y}_{3} \mathrm{Ga}_{5} \mathrm{O}_{12}+h v \rightarrow \mathrm{Y}_{3} \mathrm{Ga}_{5} \mathrm{O}_{12}+\mathrm{e}^{-}+\mathrm{h}^{+}
$$

$$
\mathrm{Ag}_{2} \mathrm{O}+h v \rightarrow \mathrm{Ag}_{2} \mathrm{O}+\mathrm{e}^{-}+\mathrm{h}^{+}
$$




$$
\begin{gathered}
\mathrm{Ag}_{2} \mathrm{O}+\mathrm{e}^{-} \rightarrow \mathrm{Ag}+\mathrm{O}_{2} \\
\mathrm{e}^{-}+\mathrm{O}_{2} \rightarrow \mathrm{O}_{2}{ }^{-} \\
\mathrm{O}_{2}^{-}+\mathrm{H}_{2} \mathrm{O} \rightarrow \mathrm{H}_{2} \mathrm{O}^{\cdot}+\mathrm{OH}^{\cdot} \\
\mathrm{H}_{2} \mathrm{O}^{\cdot}+\mathrm{H}_{2} \mathrm{O} \rightarrow \mathrm{H}_{2} \mathrm{O}_{2}+\mathrm{OH}^{\circ} \\
\mathrm{H}_{2} \mathrm{O}_{2} \rightarrow 2 \mathrm{OH}^{\cdot} \\
\mathrm{h}^{+}+\mathrm{OH}^{-} \rightarrow \mathrm{OH}^{\cdot} \\
\mathrm{h}^{+}+\mathrm{RhB}^{-} \mathrm{CO}_{2}+\mathrm{H}_{2} \mathrm{O}
\end{gathered}
$$

The photocatalytic activity of the $\mathrm{Ag}_{2} \mathrm{O}$ modified YGG sample was also tested under simulated solar radiation as shown in Fig. 8(c). Among the different light sources used in this experiment, the visible light has the shortest penetration depth, and thus the masking effect was major. ${ }^{48}$ Besides, the simulated solar radiation contains both UV light and visible light. It may affect significantly the photocatalytic activity of the $\mathrm{Ag}_{2} \mathrm{O}$ modified YGG sample. On the other hand, since the simulated solar radiation contains a larger portion of visible light than UV light, the simulated solar radiation cannot penetrate efficiently into the sample, leading to lower photocatalytic activity. Therefore, efficient photocatalytic activity is observed under UV light irradiation for the $\mathrm{Ag}_{2} \mathrm{O}$ modified YGG sample. This indicates that the improved photocatalytic activity is primarily due to efficient absorption of light and photoinduced charge separation.

\section{Conclusions}

The YGG spherical nanoparticles were successfully prepared by a single-step hydrothermal process. Under $355 \mathrm{~nm}$ excitation, the YGG sample exhibited a broadband blue emission with a band maximum at $435 \mathrm{~nm}$. This is attributed to the self-activated $\mathrm{Ga}-\mathrm{O}$ luminescent centers present in the host lattice. The photocatalytic activity of this sample was examined with the RhB dye solution under UV light irradiation. To enhance the photocatalytic activity, $\mathrm{Ag}_{2} \mathrm{O}$ was loaded onto the surface of YGG spherical nanoparticles. The $\mathrm{Ag}_{2} \mathrm{O}$ modified YGG spherical nanoparticles showed enhanced photocatalytic activity under UV light, and they also revealed photocatalytic activity under visible and solar light. The improved photocatalytic activity was due to the effective charge separation. The present work is expected to furnish the development of new complex oxide semiconductor materials and the use of a cocatalyst for its effective degradation of organic pollutants.

\section{Acknowledgements}

This work was supported by the National Research Foundation of Korea (NRF) Grant funded by the Korean government (MISP) (No. 2015R1A5A1037656 and No. 2013R1A1A2010037).

\section{References}

1 J. Coronado, in Design of Advanced Photocatalytic Materials for Energy and Environmental Applications, ed. J. M. Coronado, F. Fresno, M. D. Hernández-Alonso and R. Portela, Springer, London, 2013, ch. 1, pp. 1-4, DOI: 10.1007/978-1-4471-5061-9_1.

2 L. Bruner and J. Kozak, Z. Elektrochem. Angew. Phys. Chem., 1911, 17, 354-360.

3 E. Keidel, Farben-Ztg., 1929, 34, 1242-1243.

4 C. Doodeve and J. Kitchener, Trans. Faraday Soc., 1938, 34, 902-912.

5 I. Izumi, W. W. Dunn, K. O. Wilbourn, F.-R. F. Fan and A. J. Bard, J. Phys. Chem., 1980, 84, 3207-3210.

6 M. Anpo, Pure Appl. Chem., 2000, 72, 1265.

7 Z. Lin, A. Orlov, R. M. Lambert and M. C. Payne, J. Phys. Chem. B, 2005, 109, 20948-20952.

8 X.-Y. Zhang, H.-P. Li, X.-L. Cui and Y. Lin, J. Mater. Chem., 2010, 20, 2801-2806.

9 J. Fei and J. Li, Adv. Mater., 2015, 27, 314-319.

10 A. Ibhadon and P. Fitzpatrick, Catalysts, 2013, 3, 189.

11 C. S. Lima, K. A. Batista, A. García Rodríguez, J. R. Souza and K. F. Fernandes, Sol. Energy, 2015, 114, 105-113.

12 H. Yu, R. Liu, X. Wang, P. Wang and J. Yu, Appl. Catal., B, 2012, 111-112, 326-333.

13 H. Chu, X. Liu, J. Liu, J. Li, T. Wu, H. Li, W. Lei, Y. Xu and L. Pan, Mater. Sci. Eng., B, 2016, 211, 128-134.

14 P. Kamal Kumar, G. Ramesh and P. K. Giri, Nanotechnology, 2016, 27, 315703.

15 R. Kumar, R. El-Shishtawy and M. Barakat, Catalysts, 2016, 6, 76.

16 X. Jiang, Y. Wang and C. Pan, J. Alloys Compd., 2011, 509, L137-L141.

17 G. Feng, S. Liu, Z. Xiu, Y. Zhang, J. Yu, Y. Chen, P. Wang and X. Yu, J. Phys. Chem. C, 2008, 112, 13692-13699.

18 J. Wang, Y. Li, L. Zhang, J. Q. Gao, B. X. Wang, Q. Yang and P. Fan, Russ. J. Phys. Chem. A, 2014, 88, 149-157.

19 H. Shi, C. Zhu, J. Huang, J. Chen, D. Chen, W. Wang, F. Wang, Y. Cao and X. Yuan, Opt. Mater. Express, 2014, 4, 649-655.

20 H. K. Yang and J. H. Jeong, J. Phys. Chem. C, 2010, 114, 226-230.

21 L. K. Bharat, L. S. Reddy and J. S. Yu, Mater. Lett., 2015, 144, 85-89.

22 H. Wu, Y. Hu, W. Zhang, F. Kang, N. Li and G. Ju, J. Sol-Gel Sci. Technol., 2012, 62, 227-233.

23 L. Krishna Bharat, B. Vengala Rao and J. S. Yu, Chem. Eng. J., 2014, 255, 205-213. 
24 X. Jiang, Y. Pan, S. Huang, X. A. Chen, J. Wang and G. Liu, J. Mater. Chem. C, 2014, 2, 2301-2306.

25 Q. Chen and X. Shen, Cryst. Growth Des., 2010, 10, 3838-3842.

26 X. Yang, Z. Fu, G. Liu, C. Zhang, Y. Wei, Z. Wu and T. Sheng, RSC Adv., 2015, 5, 70220-70228.

27 R. Viswanatha and D. D. Sarma, in Nanomaterials Chemistry, Wiley-VCH Verlag GmbH \& Co. KGaA, 2007, ch. 4, pp. 139170, DOI: 10.1002/9783527611362.

28 L. Krishna Bharat, J. Y. Park and J. S. Yu, Chem. Eng. J., 2014, 240, 179-186.

29 A. C. Taş, P. J. Majewski and F. Aldinger, J. Am. Ceram. Soc., 2002, 85, 1421-1429.

30 L. Krishna Bharat, S. H. Lee and J. S. Yu, Mater. Res. Bull, 2014, 53, 49-53.

31 V. Venkatramu, S. F. Leon-Luis, U. R. Rodriguez-Mendoza, V. Monteseguro, F. J. Manjon, A. D. Lozano-Gorrin, R. Valiente, D. Navarro-Urrios, C. K. Jayasankar, A. Munoz and V. Lavin, J. Mater. Chem., 2012, 22, 13788-13799.

32 W. Lü, H. Zhou, G. Chen, J. Li, Z. Zhu, Z. You and C. Tu, J. Phys. Chem. C, 2009, 113, 3844-3849.

33 V. Monteseguro, M. Rathaiah, K. Linganna, A. D. LozanoGorrín, M. A. Hernández-Rodríguez, I. R. Martín, P. Babu, U. R. Rodríguez-Mendoza, F. J. Manjón, A. Muñoz, C. K. Jayasankar, V. Venkatramu and V. Lavín, Opt. Mater. Express, 2015, 5, 1661-1673.

34 D. Majumdar and D. Chatterjee, J. Appl. Phys., 1991, 70, 988-992.
35 O. Ahmed Zelekew and D.-H. Kuo, Phys. Chem. Chem. Phys., 2016, 18, 4405-4414.

36 C.-M. Liu, J.-W. Liu, G.-Y. Zhang, J.-B. Zhang, Q.-S. Wu, Y.-Y. $\mathrm{Xu}$ and Y.-Q. Sun, RSC Adv., 2015, 5, 32333-32342.

37 N. Liang, M. Wang, L. Jin, S. Huang, W. Chen, M. Xu, Q. He, J. Zai, N. Fang and X. Qian, ACS Appl. Mater. Interfaces, 2014, 6, 11698-11705.

38 C. Sun and C. Tu, Mater. Express, 2012, 2, 145-150.

39 K. M. Krishna, G. Anoop and M. K. Jayaraj, J. Electrochem. Soc., 2007, 154, J310-J313.

40 X. Xu, Z. Xu, Y. Hou, Y. Su, X. Xu, X. Wang and W. Tong, Appl. Phys. Lett., 2000, 77, 672-674.

41 G. Li, C. Peng, C. Li, P. Yang, Z. Hou, Y. Fan, Z. Cheng and J. Lin, Inorg. Chem., 2010, 49, 1449-1457.

42 V. Chirmanov, P. C. Stanish, A. Layek and P. V. Radovanovic, J. Phys. Chem. C, 2015, 119, 5687-5696.

43 B. K. Kang, H. D. Lim, S. R. Mang, K. M. Song, M. K. Jung, S.-W. Kim and D. H. Yoon, Langmuir, 2015, 31, 833-838.

44 S. K. Sharma, S. Som, R. Jain and A. K. Kunti, J. Lumin., 2015, 159, 317-324.

45 S. Gu, Y. Chen, X. Yuan, H. Wang, X. Chen, Y. Liu, Q. Jiang, Z. Wu and G. Zeng, RSC Adv., 2015, 5, 79556-79564.

46 S. Ma, J. Xue, Y. Zhou and Z. Zhang, J. Mater. Chem. A, 2014, 2, 7272-7280.

47 W. Zhou, H. Liu, J. Wang, D. Liu, G. Du and J. Cui, ACS Appl. Mater. Interfaces, 2010, 2, 2385-2392.

48 W. R. Siah, H. O. Lintang, M. Shamsuddin, H. Yoshida and L. Yuliati, Catal. Sci. Technol., 2016, 6, 5079-5087. 